\title{
Observations of barrier island length explained using an exploratory morphodynamic model
}

\author{
Pieter C. Roos, ${ }^{1}$ Henk M. Schuttelaars, ${ }^{2}$ and Ronald L. Brouwer ${ }^{3}$ \\ Received 19 June 2013; revised 5 August 2013; accepted 8 August 2013; published 20 August 2013.
}

[1] Barrier coasts display a chain of islands, separated by tidal inlets that connect a back-barrier basin to a sea or ocean. Observations show that barrier island length generally decreases for increasing tidal range and increasing basin area. However, this has neither been reproduced in model studies nor explained from the underlying physics. This is the aim of our study. Here we simulate barrier coast dynamics by combining a widely used empirical relationship for inlet dynamics with a process-based model of the tidal hydrodynamics. Our model results show stable inlet systems with more than one inlet open that support the observed qualitative relationships and fit in existing barrier coast classifications. To explain this, we identify a competition between a destabilizing mechanism (bottom friction in inlets, tending to reduce the number of open inlets) and a stabilizing one (spatially varying pressure gradients over the inlets, tending to keep the inlets open). Citation: Roos, P. C., H. M. Schuttelaars, and R. L. Brouwer (2013), Observations of barrier island length explained using an exploratory morphodynamic model, Geophys. Res. Lett., 40, 4338-4343, doi:10.1002/grl.50843.

\section{Introduction}

[2] Barrier coasts, covering about $10 \%$ of the world's coastline [Glaeser, 1978; Stutz and Pilkey, 2011], are densely populated areas subject to the potentially conflicting interests of economy, coastal safety, and ecology. They usually display a chain of barrier islands, separated by tidal inlets that connect a back-barrier basin to a sea or ocean [De Swart and Zimmerman, 2009]. Observations from mesotidal barrier coasts, e.g., the Wadden Sea [Wolff, 1986; Oost and De Boer, 1994] (see Figures 1a and 1b), Georgia Bight [Hayes, 1979, 1994; Fitzgerald, 1996], and Long Island [Fitzgerald, 1996], show that barrier island length generally decreases for increasing tidal range. Barrier island length is also observed to decrease for increasing lagoon area [Stutz and Pilkey, 2011; Davis and Hayes, 1984]. To reproduce and explain these relationships, we combine an empirical relationship for inlet dynamics with process-based modeling of the water motion.

\footnotetext{
${ }^{1}$ Water Engineering and Management, University of Twente, Enschede, Netherlands.

${ }^{2}$ Institute of Applied Mathematics, Delft University of Technology, Delft, Netherlands.

${ }^{3}$ Section of Hydraulic Engineering, Delft University of Technology, Delft, Netherlands.
}

Corresponding author: P. C. Roos, Department of Water Engineering and Management, University of Twente, P.O. Box 217, NL-7500 AE Enschede, Netherlands. (p.c.roos@utwente.nl)

(C)2013. American Geophysical Union. All Rights Reserved. 0094-8276/13/10.1002/grl.50843
[3] There are various empirical relationships describing tidal inlets [LeConte, 1905; O'Brien, 1931; Escoffier, 1940; Bruun and Gerritsen, 1959]. Recently, process-based support for these concepts has been provided by complex simulation models applied to single inlet systems [Tung et al., 2009; Nahon et al., 2012]. In this contribution, we use the stability concept by Escoffier [1940]. Based on a balance between wave-driven import and tide-driven export of sediment, he proposed an equilibrium condition $U=U_{\text {eq }}$ for the ebb-tidal flow velocity amplitude $U$ in the inlet (Figure 1c). If $U>U_{\mathrm{eq}}$, the inlet erodes, if $U<U_{\mathrm{eq}}$, it accretes, where $U_{\text {eq }}$ is the equilibrium velocity. To determine the tidal flow velocity in the inlet, Escoffier [1940] applied a simple lumped-parameter model which assumes a spatially uniform surface elevation in the basin. The resulting closure curve (Figure 1c) displays one unstable and one stable equilibrium value of the inlet's cross-sectional area $A$ (or no equilibrium at all if $U<U_{\mathrm{eq}}$ ).

[4] Extending Escoffier's approach to two or more inlets draining a single basin, assuming a spatially uniform surface elevation, has shown that all systems are unstable [e.g., Van de Kreeke, 1990a, 1990b]. This implies that one inlet will remain open, whereas all other inlets close. As suggested by Escoffier [1977], accounting for spatial variations in the basin's surface level may lead to stable equilibria with more than one inlet open. For double inlet systems, this was recently confirmed using models in which these spatial variations were included either explicitly [Van de Kreeke et al., 2008; Brouwer et al., 2012b; De Swart and Volp, 2012] or parametrically [Brouwer et al., 2012a].

[5] So far, there have been no model studies that explain the existence of stable barrier coasts with more than one inlet open, let alone the observed relationships in inlet spacing. To tackle this problem, we develop an exploratory morphodynamic model that simulates the dynamics of mesotidal barrier coasts with initially an arbitrary number of tidal inlets, while explicitly accounting for spatial variations in the tide levels in the back-barrier lagoon and in the ocean (section 2). The model results reveal the existence of stable equilibrium states with more than one inlet open, and the number of inlets depends on the tidal range and basin width (section 3). Both aspects of these results are then qualitatively explained from the physical mechanisms (section 4.1) and embedded in the observational literature (section 4.2). Finally, we present the conclusions (section 5).

\section{Model}

[6] We present a new process-based model that simulates the evolution of multiple inlet systems. It is of the exploratory type [Murray, 2003], implying that we include only the essential processes while qualitatively reproducing 


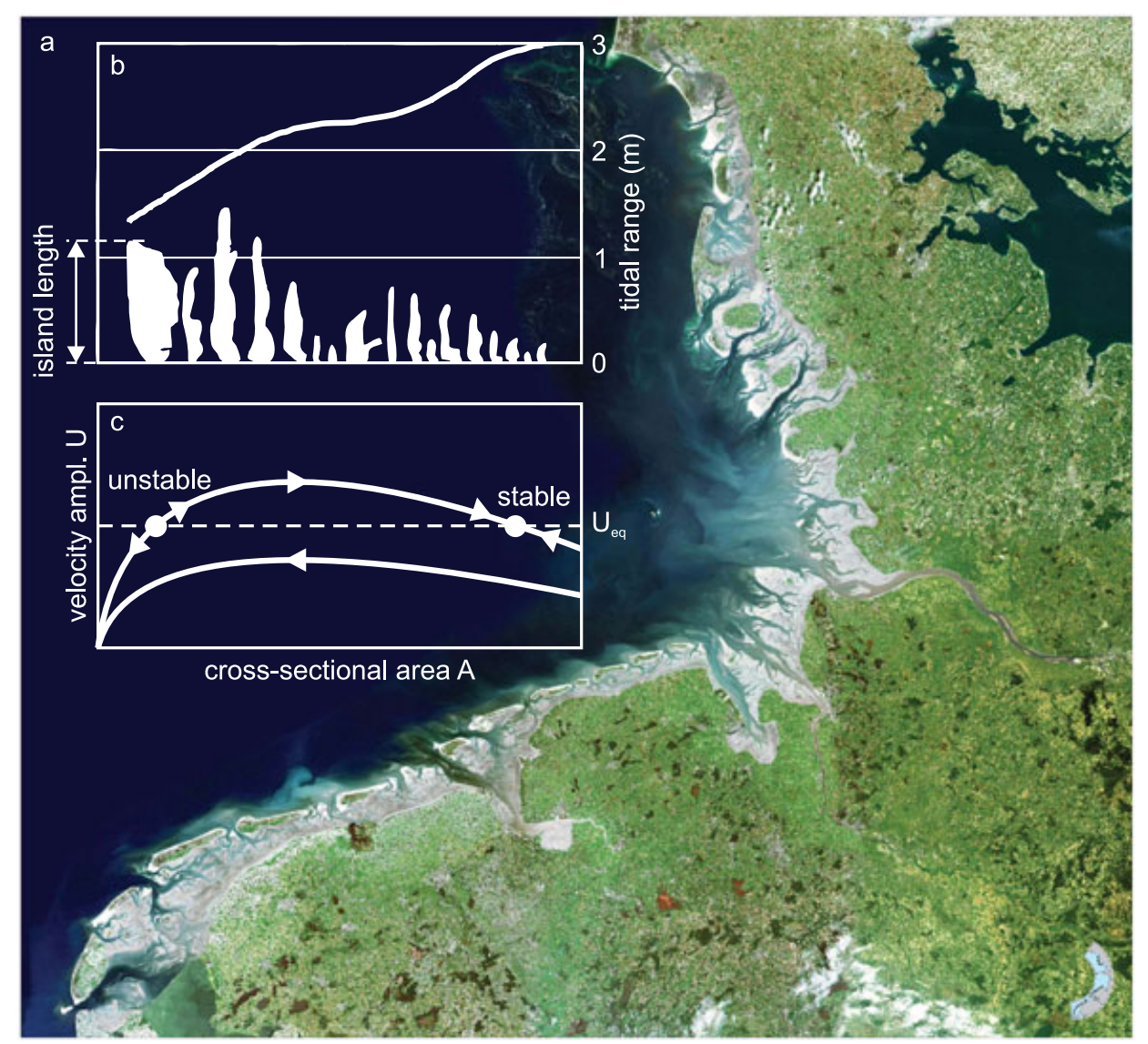

Figure 1. (a) Satellite image of the Wadden Sea (copyright: Eurimage 2003, Common Wadden Sea Secretariat, Brockmann Consult). (b) Inset showing the relationship between tidal range and barrier island length (adapted from Wolff [1986]). (c) Inset showing Escoffier's [1940] stability concept for a single inlet system. A so-called closure curve shows the inlet's tidal velocity amplitude $U$ versus its cross-sectional area $A$. Triangles indicate inlet evolution, showing erosion if $U>U$ eq and accretion if $U<U_{\text {eq. }}$. White dots represent equilibrium states $\left(U=U_{\text {eq }}\right)$, giving either one unstable and one stable equilibrium (upper curve) or no equilibrium at all (lower curve).

a poorly understood phenomenon, without considering sitespecific details and without expecting quantitative accuracy. Our model combines Escoffier's stability concept with a process-based hydrodynamic model for depth-averaged tidal flow in the inlets, basin, and ocean. The tidal flow pattern is calculated analytically, after which Escoffier's concept is applied to obtain the evolution of each inlet's cross-sectional area in a computationally efficient way. This enables us to systematically analyze the evolution toward equilibrium states, which is essential to discover dependencies and to identify physical mechanisms. Running a complex simulation model is unfeasible in view of the large temporal and spatial scales and the need to make extensive sensitivity analyses.

[7] Consider a multiple inlet system with $J$ inlets that connect a single rectangular basin of uniform depth $h_{\mathrm{b}}$ with a semi-infinite ocean of uniform depth $h_{\mathrm{o}}$ (Figure 2a). Note that inlets are not created by the model; they are specified by the initial geometry (or may otherwise be externally imposed at a certain moment to mimic the effect of a storm). The cross-sectional area $A_{j}$ of an individual inlet evolves according to Escoffier's principle, i.e.,

$$
\frac{\mathrm{d} A_{j}}{\mathrm{~d} t}=\frac{M}{l}\left[\left(\frac{U_{j}}{U_{\mathrm{eq}}}\right)^{3}-1\right],
$$

with inlet length $l$, wave-driven sediment import $M$ that is proportional to the cube of the equilibrium velocity $U_{\text {eq }}$, and amplitude $U_{j}$ of the cross-sectionally averaged tidal flow velocity in the inlet [De Swart and Zimmerman, 2009; Escoffier, 1940]. The parameters $l, U_{\text {eq }}$, and, hence, $M$ are all assumed to be identical for each inlet. Note that effects of wind waves are parametrically included in the values of $U_{\text {eq }}$ and hence $M$. Equation (1) is integrated numerically, assuming each inlet's shape factor $\gamma_{j}^{2}=h_{j} / b_{j}$ to be constant with $h_{j}$ the inlet depth and $b_{j}$ the width [e.g., De Swart and Zimmerman, 2009].

[8] For these short and narrow inlets, the required flow amplitudes $U_{j}$ follow from a balance among inertia, depthdependent bottom friction, and the pressure gradient over each inlet [De Swart and Zimmerman, 2009]:

$$
\frac{\mathrm{d} u_{j}}{\mathrm{~d} t}+\frac{r_{j} u_{j}}{h_{j}}=-g \frac{\left\langle\eta_{\mathrm{o}}\right\rangle_{j}-\left\langle\eta_{\mathrm{b}}\right\rangle_{j}}{l} .
$$

Here, $u_{j}$ is the instantaneous cross-sectionally averaged tidal flow velocity in the inlet and $r_{j}=8 c_{\mathrm{d}} U_{j} /(3 \pi)$ is a linear bottom friction coefficient, involving a drag coefficient $c_{\mathrm{d}}=2.5 \times 10^{-3}$ and a velocity scale $U_{j}$ [Lorentz, 1922]. Furthermore, the pressure gradient is proportional to the ratio of gravitational acceleration $g$ and inlet length $l$ as well as the difference between the cross-sectionally aver- 

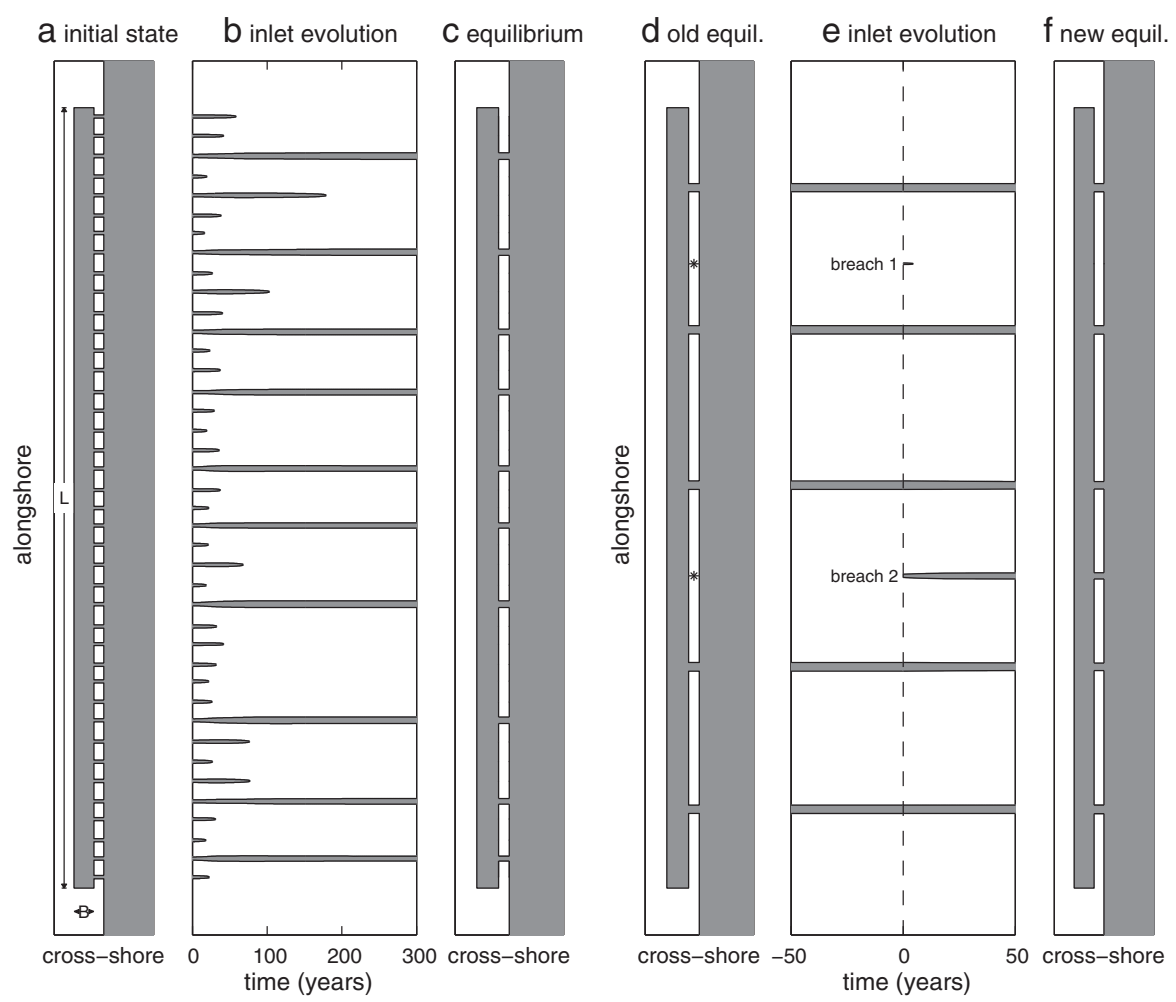

Figure 2. Model geometry and example of simulations, using parameter values typical for Georgia Bight (Table 1). (a) Plan view of initial geometry showing a rectangular basin, connected to a sea/ocean by $J_{\text {init }}=40$ randomized inlet channels. (b) Evolution, the horizontal bars showing that most inlets close and only 10 remain open. (c) Equilibrium state satisfying $U_{j}=U_{\text {eq }}$ for all 10 open inlets. (d) Equilibrium state with five inlets, before - to mimic a storm event (at $t=0$ ) - two breaches are added to two of the barrier islands (stars). (e) Evolution, showing that one breach closes and the other stays open. (f) New equilibrium with six inlets.

aged elevations $\left\langle\eta_{\mathrm{o}}\right\rangle_{j}$ at the ocean side and $\left\langle\eta_{\mathrm{b}}\right\rangle_{j}$ at the basin side of inlet $j$.

[9] The ocean's surface elevation $\eta_{\mathrm{o}}$ is the superposition of the prescribed tidal wave and the waves radiating away from each inlet. The prescribed tidal wave is of the form $\eta_{\text {oforc }}=\frac{1}{2} H_{\text {tide }} \cos \left(k_{0} y-\omega t\right)$ with tidal range $H_{\text {tide }}$, wave number $k_{\mathrm{o}}$, alongshore coordinate $y$, and angular frequency $\omega$. For $k_{0}= \pm \omega / \sqrt{g h_{0}}$, this gives a wave propagating alongshore; for $k_{\mathrm{o}}=0$ a normally incident one. To analytically calculate the radiating waves, we apply the near-field form of Buchwald's [1971] oceanic Green's function (without rotation), satisfying the linearized shallow water equations. Likewise, the basin's surface elevation $\eta_{\mathrm{b}}$ is the superposition of the cooscillations induced by the flow through each inlet. These contributions are calculated analytically using the (truncated) Green's function for the closed basin [Sommerfeld, 1949; Miles, 1971], satisfying the linear shallow water equations with bottom friction (with coefficient $r_{\mathrm{b}}=8 c_{\mathrm{d}} U_{\mathrm{b}} /(3 \pi)$ involving velocity scale $\left.U_{\mathrm{b}}\right)$. The (complex) amplitudes of basin and ocean elevation induced by an individual inlet are thus proportional to that of the flow through that inlet. This finally gives a set of coupled algebraic equations for all $U_{j}$. An iterative procedure is then applied to ensure that the velocity scales $U_{j}$ and $U_{\mathrm{b}}$, used to calculate the friction coefficients $r_{j}$ and $r_{\mathrm{b}}$, agree with the solution. Note that we ignore other natural phenomena, such as complex channel-shoal bathymetry, tidal watersheds, inlet migration, fluvial influences, and alongshore variations in basin width and grain size.

\section{Results}

[10] We have simulated the evolution of a barrier coast with initially a large number of inlets, randomized in terms of their position, initial width, and depth (Figure 2a). We subsequently apply parameter values that are typical for the Georgia Bight and Wadden Sea (Table 1). The central

Table 1. Parameter Values for Georgia Bight and Wadden Sea

\begin{tabular}{|c|c|c|c|}
\hline Parameter & Symbol (dim.) & Georgia Bight & Wadden Sea \\
\hline Tidal range & $H_{\text {tide }}(\mathrm{m})$ & 2 (Figure 3a) & 2 (Figure $3 b$ ) \\
\hline Tidal frequency & $\omega\left(\mathrm{rad} \mathrm{s}^{-1}\right)$ & $1.41 \times 10^{-4}$ & $1.41 \times 10^{-4}$ \\
\hline Basin width & $B(\mathrm{~km})$ & 2 (Figure 3c) & 10 (Figure $3 d$ ) \\
\hline Basin length $^{\mathrm{a}}$ & $L(\mathrm{~km})$ & 100 & 100 \\
\hline Basin depth & $h_{\mathrm{b}}(\mathrm{m})$ & 2 & 5 \\
\hline Ocean depth & $h_{\mathrm{o}}(\mathrm{m})$ & 30 & 20 \\
\hline Wave number & $k_{\mathrm{o}}\left(\mathrm{rad} \mathrm{m}^{-1}\right)$ & 0 & $8.2 \times 10^{-6}$ \\
\hline Inlet length ${ }^{\mathrm{b}}$ & $l(\mathrm{~km})$ & 1 & 5 \\
\hline Inlet depth ${ }^{\mathrm{c}, \mathrm{d}}$ & $h_{j}(\mathrm{~m})$ & 2 & 5 \\
\hline Inlet width ${ }^{\mathrm{c}, \mathrm{d}}$ & $b_{j}(\mathrm{~km})$ & 0.4 & 1.0 \\
\hline Inlet shape factor ${ }^{\mathrm{c}}$ & $\gamma_{j}^{2}(-)$ & 0.005 & 0.005 \\
\hline Number of inlets ${ }^{\mathrm{d}}$ & $J_{\text {init }}(-)$ & 40 & 40 \\
\hline Equil. velocity & $U_{\mathrm{eq}}\left(\mathrm{m} \mathrm{s}^{-1}\right)$ & 1.0 & 1.0 \\
\hline Sediment import & $M\left(\mathrm{~m}^{3} \mathrm{yr}^{-1}\right)$ & $1 \times 10^{5}$ & $1 \times 10^{6}$ \\
\hline Num. time step ${ }^{\mathrm{e}}$ & $\Delta t(\mathrm{yr})$ & 0.5 & $1.0-2.0$ \\
\hline
\end{tabular}

${ }^{a}$ Smaller than actual basin length to limit computational time, but large enough to allow for sufficient resolution in inlet spacing.

${ }^{b}$ Identical for all inlets because of model geometry (Figure 2a).

${ }^{\mathrm{c}}$ These are mean values; the individual widths and depths (and thus shape factors) are randomized around these values.

${ }^{\mathrm{d}}$ Values characterizing the initial state.

${ }^{\mathrm{e}}$ In the forward Euler discretization of equation (1). 

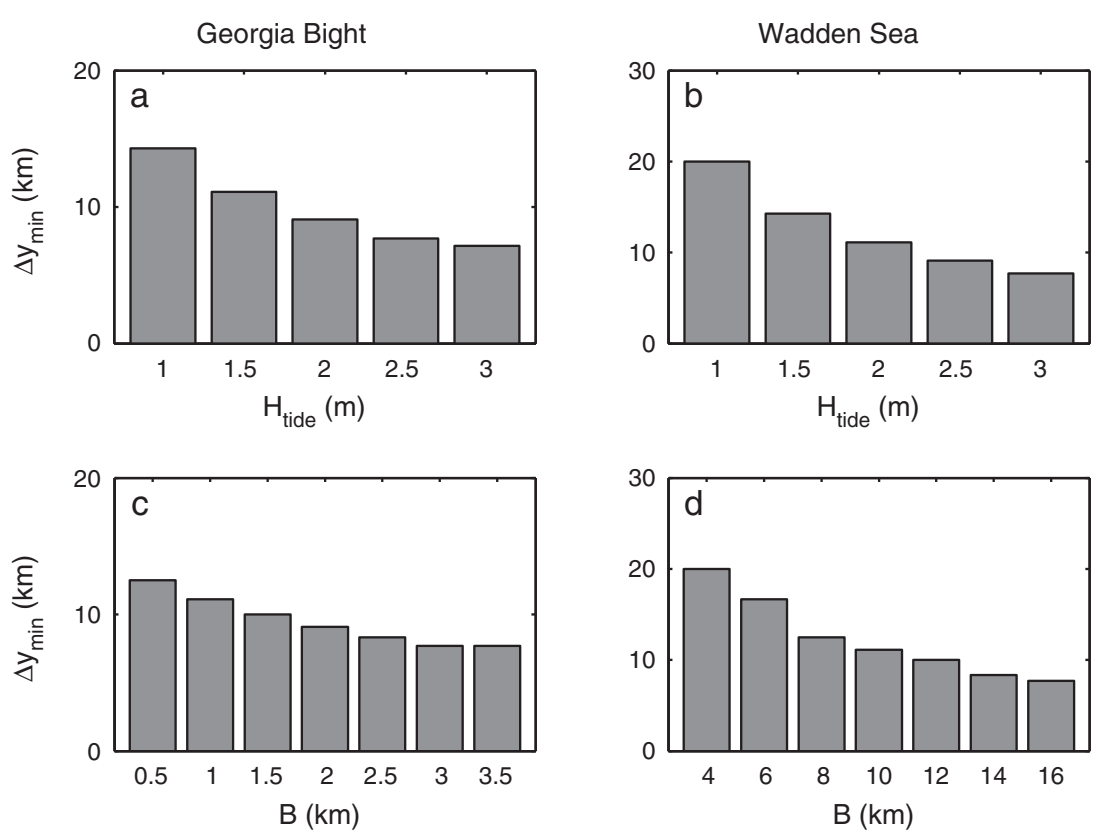

Figure 3. Modeled inlet spacing dependencies. Minimum average inlet spacing $\Delta y_{\min }=L / J_{\max }$ as a function of (top) tidal range $H_{\text {tide }}$ and (bottom) basin width $B$, for parameter values characterizing (left) Georgia Bight and (right) Wadden Sea. Each bar is based on a $J_{\max }$-value that is the maximum over an ensemble of 20 simulations with a randomized initial configuration (example in Figure 2). Parameter values are shown in Table 1.

part of the Georgia Bight barrier system is mesotidal with a normally incident tidal wave with a tidal range of about $2 \mathrm{~m}$, a wave height of $0.8 \mathrm{~m}$ and a littoral drift in the order of $10^{5} \mathrm{~m}^{3} \mathrm{yr}^{-1}$ [Hayes, 1994]. The geometrical characteristics (basin width $\sim 2 \mathrm{~km}$, basin depth $\sim 2 \mathrm{~m}$, and inlet length $\sim 1 \mathrm{~km}$ ) are estimated from Amante and Eakins [2009]. Because these are rough estimates, we will make a sensitivity analysis with respect to these parameters. The Wadden Sea barrier system is also mesotidal, with a tidal wave propagating along the coast with a tidal range of about $2 \mathrm{~m}$ (see Figure 1a), a typical wave height of about $1 \mathrm{~m}$ and a littoral drift in the order of $10^{6} \mathrm{~m}^{3} \mathrm{yr}^{-1}$ [Oost and De Boer, 1994; Van de Kreeke, 2006]. The geometrical characteristics (basin width $\sim 10 \mathrm{~km}$, basin depth $\sim 5 \mathrm{~m}$ and inlet length $\sim 5 \mathrm{~km}$ ) have been estimated from Oost and De Boer [1994].

[11] Each simulation shows a gradual process in which some inlets close (see the horizontal bars that become narrower and disappear in Figure 2b), which eventually leads to an equilibrium characterized by $U_{j}=U_{\text {eq }}$ for all open inlets (Figure 2c). The time scale of this evolution is controlled by the quantity $A l / M$ (with $A$ the typical scale for the inlets' cross-sectional areas in equilibrium); it is about 30 years for the default Georgia Bight parameter values. This demonstrates an important first result: our model allows for stable equilibrium states with more than one inlet open. Here the concept of stability within our morphodynamic model is used in a mathematical sense: when the cross-sections are slightly perturbed, the system will return to its equilibrium. Note that external changes are absent.

[12] Our simulations, carried out for a given barrier system and forcing conditions but with a different number of initial inlets $J$ in different randomized configurations, reveal a maximum number $J_{\max }$ of open inlets, corresponding to what we call a saturated barrier coast (example in Figure 2c). Furthermore, this system may also be in equilibrium with the same number of inlets located differently, or with a smaller number of inlets (nonsaturated coast, see e.g., Figures $2 \mathrm{~d}$ and $2 \mathrm{f}$ ). As illustrated in Figures $2 \mathrm{~d}-$ $2 \mathrm{f}$, newly formed inlets, externally added, e.g., to mimic the effects of a storm event, may either close or remain open (see Figure 2e), which results in a new equilibrium (Figure $2 \mathrm{f}$ ). In any case, this new equilibrium cannot contain more inlets than $J_{\max }$.

[13] Directly associated with the maximum number of inlets $J_{\max }$ is a minimum average inlet spacing $\Delta y_{\min }$, defined as

$$
\Delta y_{\min }=\frac{L}{J_{\max }}
$$

By simulating the evolution toward equilibrium for different values of the tidal range and basin width, we investigate the dependency of $\Delta y_{\min }$ on the tidal range and lagoon area. Each set of simulations represents a stretch of barrier coast for which the tidal conditions are constant. Using both Georgia Bight and Wadden Sea parameter values, our modeled inlet spacing is found to decrease for increasing tidal range (Figures 3a, 3b) and for increasing basin width (Figures 3c, 3d). Sensitivity analysis with respect to water depth shows that inlet spacing increases for increasing basin depth, and we find hardly any dependency on ocean depth. Moreover, inlet spacing is found to increase for increasing inlet length.

\section{Discussion}

\subsection{Physical Mechanisms}

[14] Our model results, i.e., the existence of stable equilibria with multiple inlets open and the resulting dependencies in Figure 3, are explained by a competition between two 

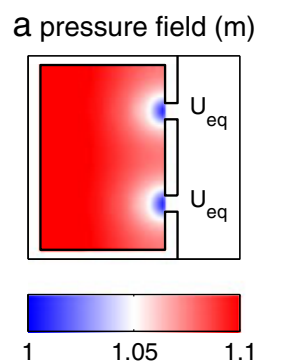

e uniform basin: unstable

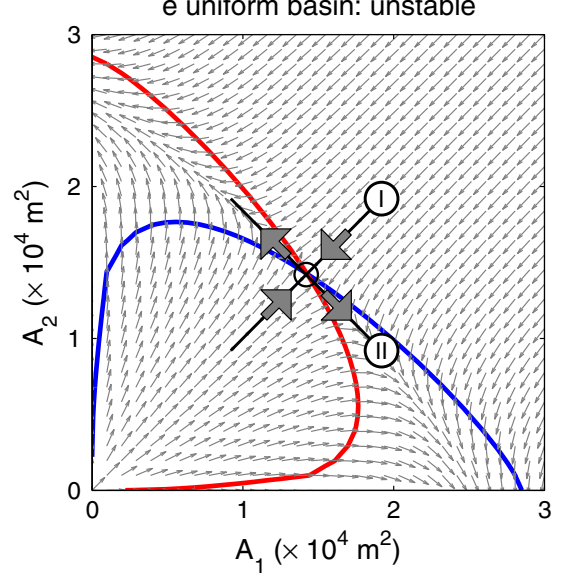

C response II (mm)
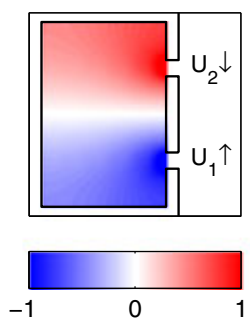

f spatial variations: stable

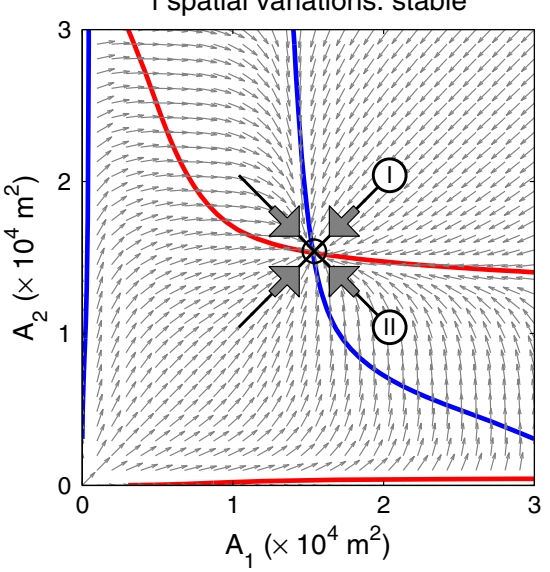

Figure 4. Illustration of stabilizing mechanism. (a) Pressure field in the basin driving the ebb flow for a symmetric double inlet system in equilibrium, without bottom friction in the basin. (b, c) Pressure responses to the bottom-frictionally induced velocity changes (here $\pm 0.01 \mathrm{~m} \mathrm{~s}^{-1}$ for perturbations I and II, respectively. (d) Same as Figure 4c but now for smaller inlet spacing $(4 \mathrm{~km})$. (e, f) Examples of flow charts showing an unstable equilibrium when assuming a spatially uniform surface elevation in the basin and a stable equilibrium when including spatial variations. $U_{j}=U_{\mathrm{eq}}$-contours in blue (inlet 1) and red (inlet 2); arrows indicate the system's tendency. Parameter values for the Georgia Bight as given in Table 1, except $L=20 \mathrm{~km}, B=10 \mathrm{~km}$; inlet spacing $\Delta y=10 \mathrm{~km}$.

mechanisms. The first is associated with bottom friction in the inlets, represented by the second term in equation (2). Since bottom friction depends on depth $h_{j}=\gamma_{j} A_{j}^{1 / 2}$ and hence on the inlet's cross-sectional area $A_{j}$, its direct feedback on the water motion amplifies perturbations from the equilibrium value $A_{j, \text { eq }}$. For example, if $A_{j}$ is increased, also $U_{j}$ will increase (keeping the pressure gradient constant). Bottom friction in the inlets thus acts as a destabilizing mechanism. The second mechanism concerns the system's feedback on the local pressure gradients over the inlets, expressed in the right-hand side of equation (2). To clarify this competition, we consider a symmetric double inlet system, identically forced at the inlets' ocean sides (Figures $4 \mathrm{a}-4 \mathrm{c}$ ). By symmetry, there is an equilibrium satisfying $A_{1, \text { eq }}=A_{2 \text {,eq. }}$. We now identify two types of perturbations: (I) equally increasing $A_{1}$ and $A_{2}$, (II) increasing $A_{1}$ and decreasing $A_{2}$ with the same amount (Figures 4d, 4e).

[15] For type I, the bottom-frictionally induced increase in inlet velocities is overcome by the velocity reduction due to the reduced pressure gradient over the inlets (resulting from the increased tidal elevation amplitude in the basin; Figure $4 \mathrm{~b}$ ). This implies accretion and thus a return to equilibrium. This argument, not requiring spatially varying water levels in the basin, actually also explains Escoffier's single inlet stability (Figure 1c).

[16] For double inlets systems, however, we must also consider perturbation type II. Then, bottom friction alone tends to increase the velocity in inlet 1 and decrease it in inlet 2. Since the mean water level is unaffected, this triggers a local decrease of the water level at the basin side of inlet 1 and a local increase at inlet 2 (Figure $4 \mathrm{c}$ ). This affects the pressure gradients, reducing the ebb velocity in inlet 1 and increasing it in inlet 2, counteracting the destabilizing flow response from friction alone.

[17] Depending on geometry and forcing conditions, this stabilizing mechanism may prevail and lead to a stable multiple inlet configuration, provided that spatial variations are indeed included (Figures 4e, 4f). For small inlet spacing, the stabilizing mechanism is negligible compared to the destabilizing one (Figure 4d). For increasing inlet spacing, the stabilizing mechanism gains relative importance. The above competition thus implies a minimum stable inlet spacing. By Escoffier's concept, increasing tidal range or increasing basin area causes the equilibrium cross-sectional area to shift to a larger value. For increasing cross-sectional area, the stabilizing mechanism gains relative importance. Hence, the minimum stable inlet spacing indeed decreases for increasing tidal range and increasing basin area.

[18] Alternatively, decreasing wave height or littoral drift will, because of the relationship $M \sim U_{\text {eq }}^{3}$ reduce both $M$ and $U_{\text {eq }}$ (see section 2). As seen from equation (1), it is the ratio $U_{j} / U_{\text {eq }}$ that controls inlet stability, whereas $M$ determines the time scale. Hence, decreasing $U_{\text {eq }}$ while keeping $U_{j}$ constant has the same effect as increasing $U_{j}$ while keeping $U_{\text {eq }}$ fixed. This last scenario is exactly what we already studied by increasing the tidal range. In either case, the ratio $U_{j} / U_{\text {eq }}$ will increase by which the preferred inlet spacing will decrease. 


\subsection{Observations and Barrier Coast Classification}

[19] The occurrence of stable equilibria with more than one inlet open demonstrates that our model is capable of reproducing the observed existence of multiple inlet systems. In our model, external changes have been absent. However, in reality, such gradual changes occur (e.g., sea level rise, changes in wave climate). This implies that the barrier system will show transient behavior on the time scale of the changes in the forcing. Our sensitivity analysis with respect to $h_{\mathrm{o}}$ and $h_{\mathrm{b}}$ suggests a tendency for inlet spacing to gradually increase under a rising sea level.

[20] The model reproduces the observed relationship [Hayes, 1979; Wolff, 1986; Oost and De Boer, 1994; Hayes, 1994; Fitzgerald, 1996] of decreasing inlet spacing for increasing tidal range (Figures 3a, 3b). As explained in section 4.1, the same is achieved for decreasing wave activity. The additional result that minimum average inlet spacing $\Delta y_{\min }$ decreases for increasing basin surface area (Figures 3c, 3d), also in agreement with observations [Stutz and Pilkey, 2011; Davis and Hayes, 1984].

[21] In the limits of strong and weak tides, our results fit in Hayes' [1979] barrier coast classification. Following Hayes, smooth barrier coasts with few inlets are associated with microtidal conditions, short and drumstick-shaped barriers with mesotidal conditions and absence of barriers with macrotidal conditions. Later, this classification is refined by noting that it is actually the importance of tides relative to waves that matters, along with other factors such as tidal prism (and thus basin area) [Davis and Hayes, 1984]. For increasingly strong tides (relative to waves), the modeled equilibria display ever more inlets, which can be seen as a transition stage to Hayes' tide-dominated regime in which barriers are absent. Conversely, for relatively weak tides, the modeled equilibria display few inlets, resembling Hayes' wave-dominated regime.

\section{Conclusions}

[22] By combining Escoffier's inlet stability concept with a hydrodynamic model for tidal flow in multiple inlet systems, we found stable equilibria with multiple inlets. In our exploratory model, we have intentionally ignored other natural phenomena, such as complex channel-shoal bathymetry, tidal watersheds, inlet migration, fluvial influences, and alongshore variations in basin width and grain size. Even so, our model results qualitatively reproduce observed relationships in inlet spacing and agree with barrier coast classifications in the literature. Our explanation does not require tidal watersheds to preexist; they may actually be interpreted as resulting from the flow patterns.

[23] Acknowledgments. The authors thank Koen Berends, Suzanne Hulscher, Jan Ribberink, George Schramkowski, Huib de Swart, Tjerk Zitman, and an anonymous reviewer for their comments on the paper.

[24] The Editor thanks an anonymous reviewer for his/her assistance in evaluating this paper.

\section{References}

Amante, C., and B. W. Eakins, (2009), ETOPO1 1 arc-minute global relief model: Procedures, data sources and analysis, NOAA Technical Memorandum NESDIS NGDC-24, 19 pp.
Brouwer, R. L., J. van de Kreeke, and H. M. Schuttelaars (2012a), Entrance/exit losses and cross-sectional stability of double inlet systems, Est. Coast. Shelf Sci., 107, 69-80, doi:10.1016/j.ecss.2012.04.033.

Brouwer, R. L., H. M. Schuttelaars, and P. C. Roos (2012b), Influence of basin geometry on equilibrium and stability of double inlet systems, Jubilee Conference Proceedings, NCK-days 2012, University of Twente, Enschede, Netherlands, doi:10.3990/2.175.

Bruun, P., and F. Gerritsen (1959), Natural bypassing of sand at coastal inlets, J. Waterw. Harb. Div., 85, 75-107.

Buchwald, V. T. (1971), The diffraction of tides by a narrow channel, J. Fluid Mech., 46(3), 501-511, doi:10.1017/S0022112071000661.

Davis, R. A., and M. O. Hayes (1984), What is a wave-dominated coast? Mar. Geol., 60(1-4), 313-329, doi:10.1016/0025-3227(84)90155-5.

De Swart, H. E., and N. D. Volp (2012), Effects of hypsometry on the morphodynamic stability of single and multiple tidal inlet systems, J. Sea Res., 74, 35-44, doi:10.1016/j.seares.2012.05.008.

De Swart, H. E., and J. T. F. Zimmerman (2009), Morphodynamics of tidal inlet systems, Annu. Rev. Fluid Mech., 41(7), 203-229, doi:10.1146/annurev.fluid.010908.165159.

Escoffier, F. F. (1940), The stability of tidal inlets, Shore Beach, 8(4), 114-115.

Escoffier, F. F. (1977), Hydraulics and stability of tidal inlets, U.S. Army Coastal Engineering Research Center. GITI Report 13, 72 pp., Vicksburg, Mississippi.

Fitzgerald, D. M. (1996), Geomorphic variability and morphologic and sedimentologic controls on tidal inlets, J. Coast. Res., 23, 47-71.

Glaeser, J. D. (1978), Global distribution of barrier islands in terms of tectonic setting, J. Geol., 86(3), 283-298.

Hayes, M. O. (1979), Barrier island morphology as a function of tidal and wave regime, in Barrier Islands, edited by S. P. Leatherman, pp. 1-27, Academic Press, New York.

Hayes, M. O. (1994), The Georgia Bight barrier system, in Geology of Holocene Barrier Island Systems, edited by R. A. Davis, pp. 233-304, Springer-Verlag, New York.

LeConte, L. J. (1905), Notes on the improvement of river and harbour outlets in the United States, Trans. Am. Soc. Civ. Eng., LV (Dec), 306-308

Lorentz, H. A. (1922), Het in rekening brengen van den weerstand bij schommelende vloeistofbewegingen, De Ingenieur, 37, 695, In Dutch.

Miles, J. W. (1971), Resonant response of harbours: An equivalentcircuit analysis, J. Fluid Mech., 46(2), 241-265, doi:10.1017/ S002211207100051X.

Murray, A. B. (2003), Contrasting the goals, strategies, and predictions associated with simplified numerical models and detailed simulations, in Prediction in Geomorphology, edited by R. M. Iverson and P. R. Wilcock, pp. 151-165, Vol. 135 of Geophysical Monograph, AGU, Washington, D. C.

Nahon, A., X. Bertin, A. B. Fortunato, and A. Oliveira (2012), Processbased 2DH morphodynamic modeling of tidal inlets: A comparison with empirical classifications and theories, Mar. Geol., 291-294, 1-11, doi:10.1016/j.margeo.2011.10.001

O'Brien, M. P. (1931), Estuary and tidal prisms related to entrance areas, Civil Eng., 1(8), 738-739.

Oost, A. P., and P. L. De Boer (1994), Sedimentology and development of barrier islands, ebb-tidal deltas, inlets and back-barrier areas of the Dutch Wadden Sea, Senckenb. Marit., 24, 65-115.

Sommerfeld, A. (1949), Partial Differential Equations in Physics, 335 pp., Academic Press, New York.

Stutz, M. L., and O. H. Pilkey (2011), Open-ocean barrier islands: Global influence of climatic, oceanographic, and depositional settings, J. Coast. Res., 27(2), 207-222, doi:10.2112/09-1190.1.

Tung, T. T., D. J. R. Walstra, J. van de Graaff, and M. J. F. Stive (2009), Morphological modeling of tidal inlet migration and closure, J. Coast. Res., 56, 1080-1084.

Van de Kreeke, J. (1990a), Stability analysis of a two inlet-bay system, Coast. Eng., 14(6), 481-497, doi:10.1016/0378-3839(90) 90031-Q.

Van de Kreeke, J. (1990b), Can multiple inlets be stable?, Est. Coast. Shelf Sci., 30(3), 261-273, doi:10.1016/0272-7714(90)90051-R.

Van de Kreeke, J. (2006), An aggregate model for the adaptation of the morphology and sand bypassing after basin reduction of the Frisian Inlet, Coast. Eng., 53(2-3), 255-263., doi:10.1016/j.coastaleng.2005.10.013.

Van de Kreeke, J., R. L. Brouwer, T. J. Zitman, and H. M. Schuttelaars (2008), The effect of a topographic high on the morphological stability of a two-inlet bay system, Coast. Eng., 55(4), 319-332, doi:10.1016/ j.coastaleng.2007.11.010.

Wolff, W. J. (1986), De Waddenzee: Eigenschappen van een dynamisch kustgebied, Flevobericht, 252, RIJP, 11-22, In Dutch. 